\title{
Magnetic Resonance Imaging of Brain Edema in the Neonatal Rat: A Comparison of Short and Long Term Hypoxia-Ischemia
}

\author{
HELMUT RUMPEL, RETO BUCHLI, JOCHEN GEHRMANN, ADRIANO AGUZZI, OSCAR ILLI, \\ AND ERNST MARTIN
}

\author{
Division of Magnetic Resonance and Developmental Brain Research [H.R., R.B., E.M.] and Department of \\ Surgery [O.I.], University Children's Hospital, Zurich, and Department of Pathology, Institute of \\ Neuropathology, University Hospital Zurich [A.A., J.G.], Zurich, Switzerland
}

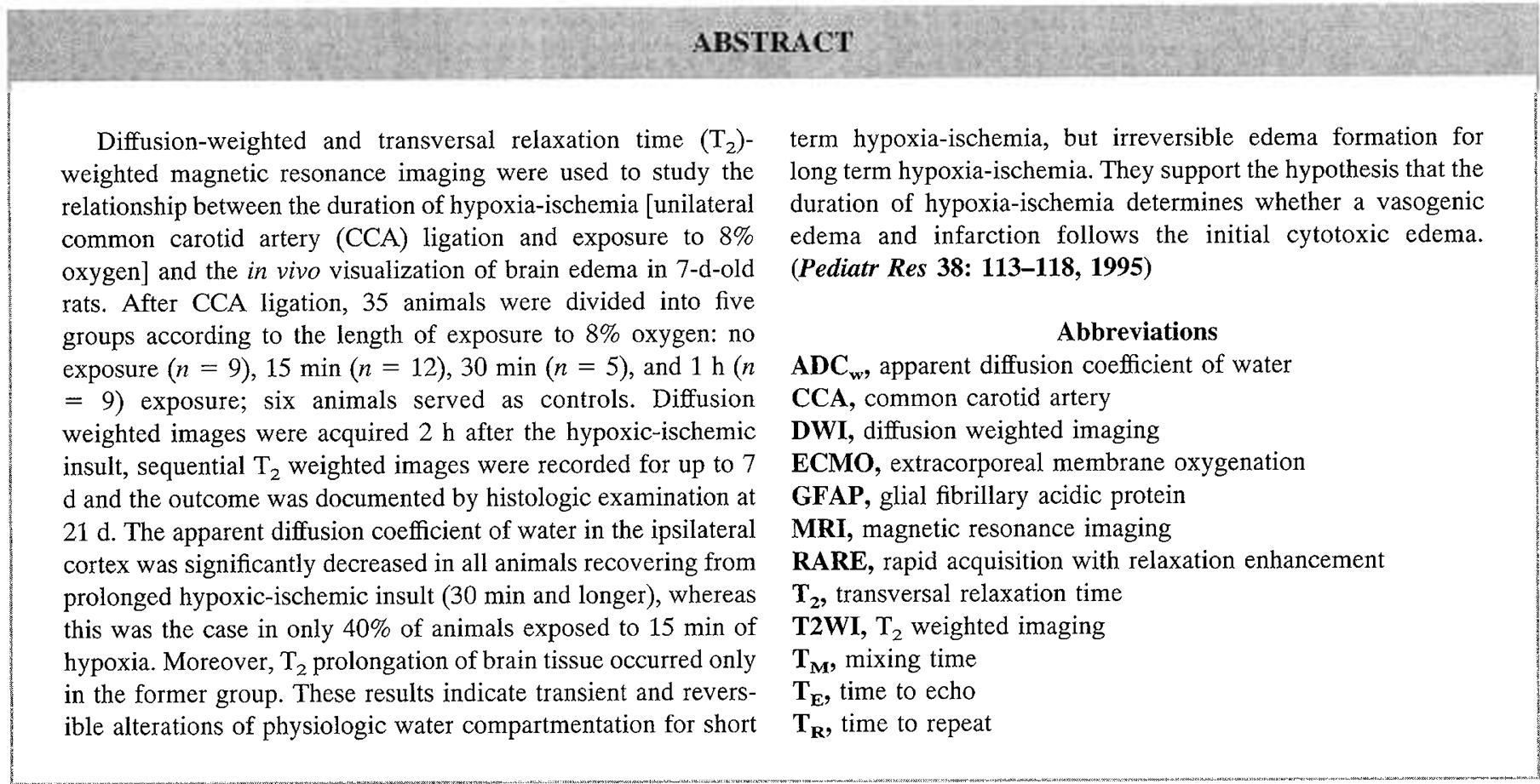

Over the past few years, a large number of animal studies have contributed to a better understanding of the pathogenesis of perinatal hypoxic-ischemic brain damage (1-8) and accompanying cerebral edema (2). This is largely due to the adaptation of the Levine preparation (9)-unilateral CCA ligation with subsequent hypoxia-to 7 -d-old neonatal rats (1), whereby unequivocal unilateral brain damage can be produced. This animal model admits to titrate the severity of hypoxicischemic lesions by varying the duration of hypoxia (exposure to $8 \%$ oxygen). The extent of brain damage to the ipsilateral hemisphere was classified as mild cerebral edema after $1 \mathrm{~h}$ of

Received August 3, 1994; accepted January 24, 1995.

Correspondence: Helmut Rumpel, Ph.D., University Children's Hospital Zurich, Steinwiesstrasse 75, CH-8032 Zurich, Switzerland.

Supported by the Prof. Max Cloëtta Foundation Zurich and the Swiss National Research Foundation, Grant 32-37811.93. hypoxia, or progressively increasing edema after $3 \mathrm{~h}$ of hypoxia (2). In particular, no brain damage was observed after CCA ligation alone $(1,2)$. This is an important observation, e.g. in the context of ECMO for severe respiratory failure in newborn infants, which involves permanent unilateral CCA ligation (10). In this regard, ECMO bears the risk of hypoxicischemic encephalopathy resulting from the combination of hypoxia and hypoperfusion during or after the procedure (11, 12).

The noninvasive nature of MRI together with the sensitivity of the contrasting MRI method to the physical environment of water molecules allows the assessment of the nature and extent of brain edema in vivo $(13,14)$. Among the large number of MRI techniques that have been developed to provide optimal contrast for various applications, DWI (15) and T2WI allow differentiation between the cytotoxic, i.e. the intracellular 
edema $(16,17)$, and the vasogenic, i.e. the extracellular edema $(16,17)$, that develop within hours and days, respectively, after a hypoxic-ischemic insult.

The purpose of this study was to combine DWI and T2WI to investigate the threshold duration of hypoxia causing brain edema in conjunction with unilateral CCA ligation. A major objective of this study on the nature and time course of brain edema has addressed the questions of 1 ) whether hyperintensity observed in DWI is always indicative of cell damage and subsequent necrosis/gliosis, and 2) whether DWI might visualize cytotoxic edema associated with a purely ischemic insult.

\section{METHOD}

Animal preparation. These studies were approved by the Animal Ethical Committee of the University of Zurich. In our laboratory, a total of 41 7-d-old postnatal Zur:SIV rats (of Spargue-Dawley background) were investigated. Six animals comprised the control group (group A), whereas 35 rats were anesthetized with diethyl ether and were then subjected to unilateral (right) CCA occlusion under a warming lamp. Nine rats were kept under room air (group B), whereas 26 rats were further exposed to $8 \%$ oxygen for spontaneous breathing. The duration of hypoxia was $15 \mathrm{~min}$ in 12/26 animals (group C), 30 min in 5/26 animals (group D), and $1 \mathrm{~h}$ in 9/26 animals (group E). All rats were kept in a thermal box which guaranteed a rectal temperature of $37 \pm 0.5^{\circ} \mathrm{C}(8)$ measured by a copper constantan thermocouple (Marlin, Cleveland, $\mathrm{OH}$ ). During the experimental MRI procedure, the rats were wrapped to maintain body temperature and were anesthetized with a mixture of oxygen and nitrous oxide (1:3) and $0.75 \%$ halothane.

MRI methods. Data were acquired on a Biospec 47/30 4.7 tesla system (Bruker-Spectrospin, Fällanden, Switzerland) using a $20-\mathrm{cm}$ actively shielded gradient insert for gradient field strengths of up to $100 \mathrm{millitesla} / \mathrm{m}$. A $25-\mathrm{mm}$ birdcage coil was tuned to $200 \mathrm{MHz}$ for radiofrequency excitation and reception of ${ }^{1} \mathrm{H}$ NMR signals. T2WI was taken by means of the multislice RARE technique (18). The interecho interval was $22 \mathrm{~ms}$. The RARE factor was 16 , and $T_{R} 4000 \mathrm{~ms}$. Spatial resolution was $115 \times 230 \mu \mathrm{m}(128$ phase encoding steps $)$ and slice thickness $2 \mathrm{~mm}$. As DWI sequence the stimulated echo imaging technique was used (19), placing the pair of diffusion sensitizing gradients symmetrically to the $T_{M}$. The sequence parameters were $T_{E} 22 \mathrm{~ms}, T_{M} 100 \mathrm{~ms}, T_{R} 1800 \mathrm{~ms}$, and a diffusion weighting factor, $b$, of $1400 \mathrm{~s} / \mathrm{mm}^{2}$ was used (20). To reduce motion artefacts, multiple averaging $(n=8)$ was performed at reduced spatial resolution in one direction (64 phase encoding steps).
MRI examination protocol. DWI was performed $2 \mathrm{~h}$ after the ischemic or hypoxic-ischemic insult; T2WI was done at 3 h, $2 \mathrm{~d}$, and $7 \mathrm{~d}$.

Histologic examination. Randomly selected rats of each group were killed for histopathologic examinations at $21 \mathrm{~d}$. The rats were perfused under deep Rompun/Ketanest anesthesia with $200 \mathrm{~mL} 4 \%$ paraformaldehyde in $0.01 \mathrm{M}$ PBS, pH 7.4. Brains were removed and postfixed in the same fixative for 3 $\mathrm{h}$ at $4^{\circ} \mathrm{C}$, then dehydrated in ascending alcohols and embedded in paraffin according to standard techniques. Four-micrometer paraffin sections were cut at the levels of the dorsal hippocampus, the dorsolateral striatum, and at the brainstem, including the cerebellum at the level of the facial nucleus. Paraffin sections were stained with hematoxylin-eosin, Luxol (Dupont, Wilmington, DE), and cresyl violet for routine histology. In addition, sections were immunostained either for the astrocytic marker using a polyclonal anti-cow GFAP (21) antibody (DAKO, Hamburg, Germany) or for the neuronal marker synaptophysin using a monoclonal anti-human synaptophysin (22) antibody (Boehringer Mannheim, Germany). Antibody detection was performed using an avidin-biotin-peroxidase complex with diaminobenzidine as substrate.

\section{RESULTS}

\section{MRI}

A total of 41 animals were investigated. According to the experimental procedure, the neonatal rats were categorized into five groups as shown in Table 1.

Group A. Figure 1 demonstrates an axial T2WI of the forebrain of an age matched control animal, which was subjected neither to carotid ligation nor to hypoxia. Note the high signal intensity of subcortical white matter in the immature brain. DWI of the control animals did not show any abnormalities.

Group B. The imaging results with regard to CCA ligation without hypoxia were uniform: no abnormal changes of signal contrast, in either DWI or in T2WI, were seen in any of the cerebral regions (Fig. 2A).

Group C. Animals exposed to $8 \%$ oxygen for $15 \mathrm{~min}$ showed two different types of MRI patterns. In $40 \%$ of the animals a hyperintensity in DWI confined to the ipsilateral cerebral cortex was followed by normal findings in T2WI after $2 \mathrm{~d}$ of recovery (Fig. $2 B$ ). Sixty percent of the animals showed no changes in MRI signal intensity, in either DWI or in T2WI.

Groups $\boldsymbol{D}$ and $\boldsymbol{E}$. In animals exposed to $8 \%$ oxygen for a duration of $30 \mathrm{~min}$ and $1 \mathrm{~h}$, respectively, DWI showed a clear

Table 1. Generation of brain edema of the ipsilateral hemisphere vs the duration of hypoxia

\begin{tabular}{|c|c|c|c|c|}
\hline Group & CCA ligation & $\begin{array}{c}\text { Duration of exposure } \\
\text { to } 8 \% \text { oxygen }\end{array}$ & $\begin{array}{l}\text { No. of animals with } \\
\text { DWI hyperintensity* } \\
\text { at } 2 \mathrm{~h} \text { of recovery }\end{array}$ & $\begin{array}{l}\text { No. of animals with } \\
\text { T2WI hyperintensity* } \\
\text { at } 2 \text { d of recovery }\end{array}$ \\
\hline A: $n=6$ & No & No exposure & None & None \\
\hline $\mathrm{B}: n=9$ & Yes & No exposure & None & None \\
\hline$C: n=12$ & Yes & $15 \mathrm{~min}$ & $5 \approx(40 \%)$ & None \\
\hline $\mathrm{D}: n=5$ & Yes & $30 \mathrm{~min}$ & 5 & 5 \\
\hline $\mathrm{E}: n=9$ & Yes & $1 \mathrm{~h}$ & 9 & 9 \\
\hline
\end{tabular}

\footnotetext{
* Compared to the MR signal intensity of the contralateral hemisphere.
} 


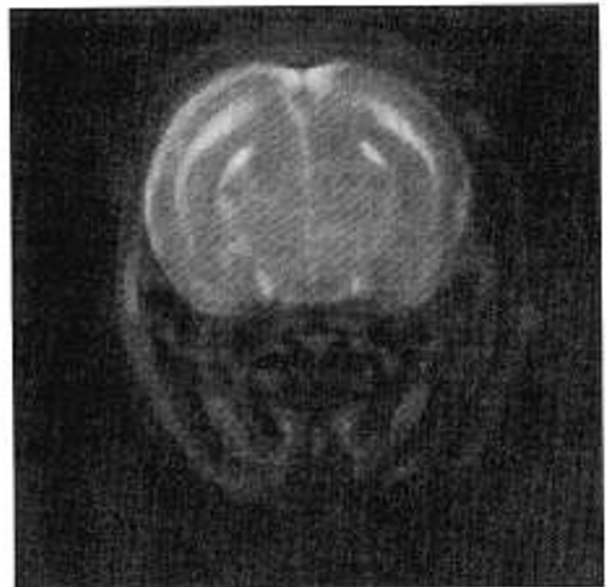

Figure 1. $T_{2}$-weighted RARE image of a 7-d-old control rat. The high signal intensity of subcortical white matter is due to the immature brain reflecting a high content of freely diffusible water.

hyperintensity in the ipsilateral hemisphere after $2 \mathrm{~h}$ of recovery. These areas involved mainly the cerebral cortex and parts of the basal ganglia. The signal intensity in the two cerebral hemispheres was slightly different in T2WI at this point (hyperintensity of $10 \%$ relative to the contralateral side in $6 / 14$ animals), but differed significantly after an interval of $2 \mathrm{~d}$. These hyperintense areas on T2WI corresponded to the hyperintense regions in DWI, but were increased in extent (Fig. 2C).

\section{Histology}

Group B. The regular neuronal structure and cell density was well preserved in all brain regions examined (Fig. 3A). GFAP immunostaining showed a strong, constitutive GFAP expression on astrocytes mainly in the white matter such as the corpus callosum but also in gray matter areas such as the hippocampus. However, only a few astrocytes were GFAP immunoreactive in the neocortex.

Group $C$. The neuronal damage and astrocytic response were more pronounced than in animals of group $B$. The histologic examination of a rat brain, in which no DWI hyperintensity was observed, revealed hypoxic damage of a few scattered neurons in the parietal cortex. Neuronal damage was evident mainly as eosinophilic neuronal shrinkage, but not by complete neuronal necrosis, and was accompanied by a weak astrocytic response (Fig. $3 B$ ). In these animals no true neuronal cell loss was observed and the astrocytic reactions were secondary to these principally reversible neuronal changes. On the other hand, in two animals, which showed a hyperintensity in DWI, true neuronal cell loss was only rarely found. However, moderate neuronal damage occurred in a columnar fashion, i.e. extending vertically from the subpial region throughout all cortical layers. In these areas, numerous hypertrophic, occasionally binucleated GFAP-immunoreactive astrocytes were observed. These lesions were most conspicuous at the border zone between the vascular territories of the anterior and of the middle cerebral artery (Fig. 3C).

Group $\boldsymbol{E}$. A large cystic and fully resorbed infarction was found on histology ipsilateral to the side of the CCA ligation. This lesion was demarcated by a pronounced astrocytic glial scar. In the periphery of the lesion, the subpial layer, and even the superficial neuronal layers were preserved in a pseudolaminar fashion. This cystic lesion extended from the striatum to the parietal cortex at the level of the dorsal hippocampus.

\section{DISCUSSION}

The findings of the present investigation should be interpreted in relation to the normal age-dependent patterns of changing signal contrast in T2WI of neonatal brains. This is a prerequisite for correct distinction between physiologic and pathologic water content in brain tissue. In control animals (group A), the unmyelinated subcortical white matter is of high signal intensity (Fig. 1) reflecting a high content of freely diffusible water that decreases with progressing myelination. It is worth noting that early detection of raising water content after hypoxia-ischemia may, therefore, be difficult.

The results answer three important questions with reference to the association between severity of hypoxia-ischemia in conjunction with unilateral CCA ligation and in vivo visualization of brain edema. 1) After unilateral ligation alone, neither the DWI contrast nor the T2WI contrast showed any significant difference between the ipsilateral and the contralateral hemisphere. 2) Cortical hyperintensity observed in DWI after $15 \mathrm{~min}$ of hypoxia, which signifies an intracellular (cytotoxic) edema, was transient, lasting less than $12 \mathrm{~h}$. It was neither followed by a vasogenic edema nor by frank infarction. This suggests that the depression of cell metabolism had not yet reached "the point of no return." 3) A duration of hypoxia of $30 \mathrm{~min}$ to $1 \mathrm{~h}$ resulted in an unequivocal cytotoxic edema, followed by a more extensive vasogenic edema after approximately $12-24 \mathrm{~h}$, which heralded cerebral infarction as confirmed by histology.

The classical method of determining the content and volume of hemispheric tissue water includes bisectioning of the forebrain, desiccation, and weighing of the specimen. The water content is then calculated as a percentage of the hemispheric weight. Inasmuch as this method maps the integrity of water molecules, only a change in total bulk water, i.e. a transfer of water from blood to tissue, would be apparent. By means of this method, an essentially linear increase in tissue volume during the course of hypoxia-ischemia has been demonstrated (2). However, the understanding of the formation of brain edema with regard to the duration of hypoxia-ischemia requires discrimination between a shift of water from the extracellular to the intracellular compartment and a net increase of interstitial fluid. The first mechanism appears to be responsible for the primary cytotoxic brain swelling during hypoxia-ischemia due to an increase of intracellular idiogenic osmoles and to a failure of the energy-dependent $\mathrm{NA}^{+} / \mathrm{K}^{+}$pumps causing transmembranous water shifts. Changes of motor properties of the cellular matrix can be visualized by the ipsilateral hyperintensity in DWI as the data from groups C, D, and E imply (Fig. 2, $B$ and $C$ ). Although the assumption of freely exchangeable water between intracellular and extracellular compartments made for diffusion measurements in healthy brains may not fully apply to hypoxic-ischemic tissue, the decline of the so-called $\mathrm{ADC}_{\mathrm{w}}(23)$ implied by the increase of signal intensity 


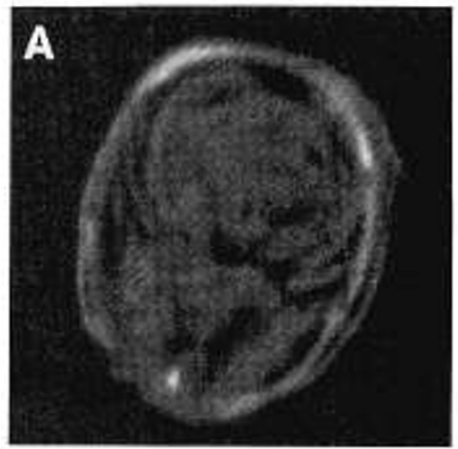

DWI at $2 \mathrm{~h}$
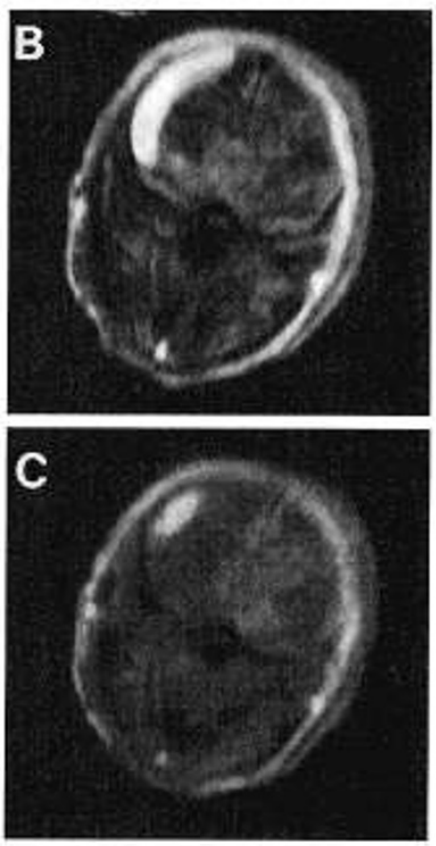

$\mathrm{DWI}$ at $2 \mathrm{~h}$
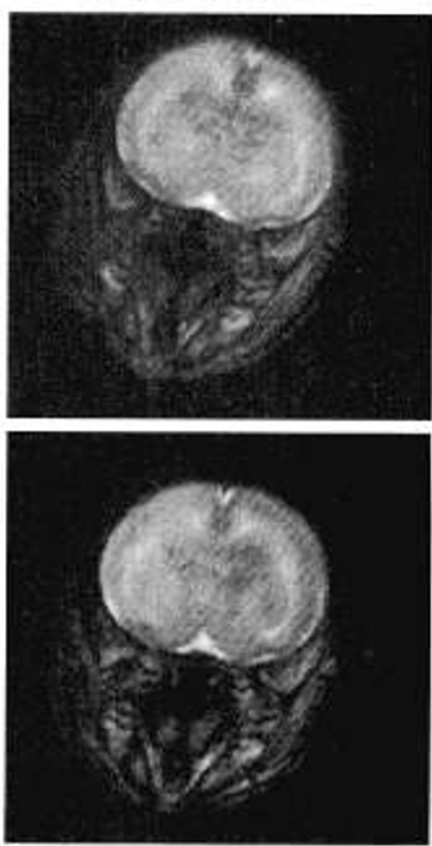

T2WI at $3 \mathrm{~h}$

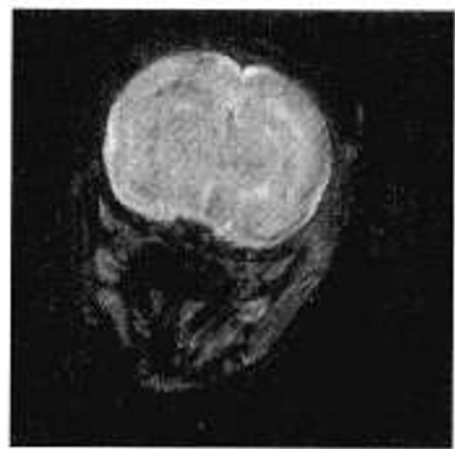

$\mathrm{T} 2 \mathrm{WI}$ at $3 \mathrm{~h}$
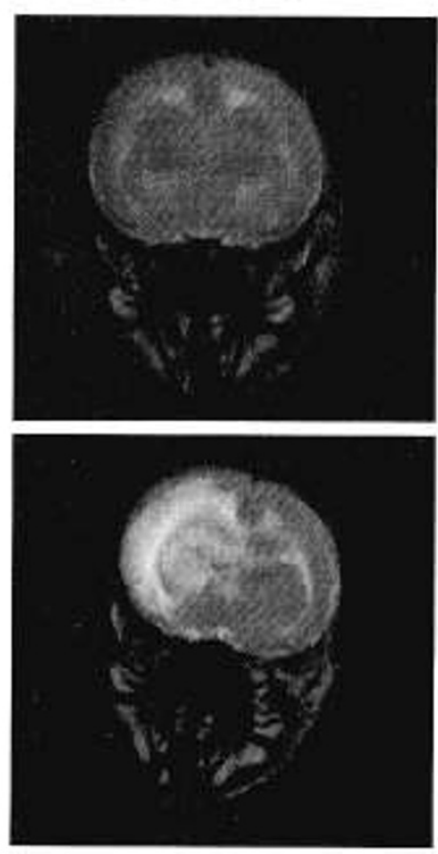

T2WI at $2 \mathrm{~d}$
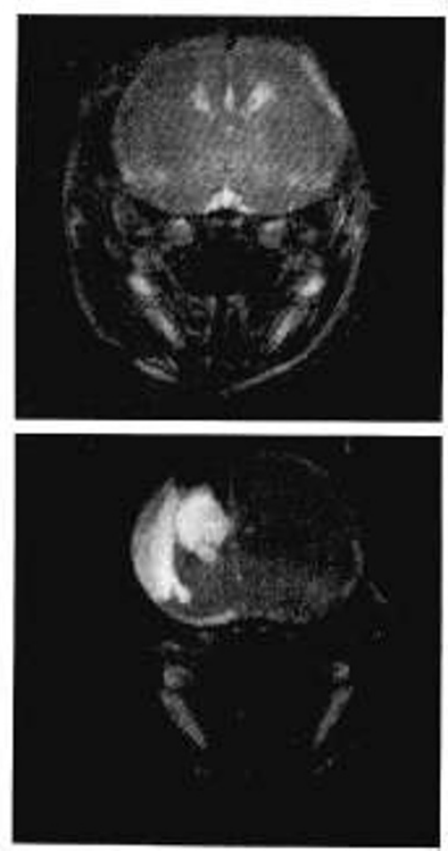

T2WI at $7 \mathrm{~d}$

Figure 2. Evolution of cerebral edema after hypoxia-ischemia. Diffusion weighted images were acquired $2 \mathrm{~h}$ after the hypoxic-ischemic insult, sequential $\mathrm{T}_{2}$-weighted images were recorded for up to $7 \mathrm{~d}$. Imaging results for CCA ligation without hypoxia $(A), 15$ min of hypoxia $(B)$, and $1 \mathrm{~h}$ of hypoxia $(C)$ are shown. No differences between the two hemispheres were seen in $A$. Cortical hyperintensity observed in DWI was transient and was not followed by an ipsilateral hyperintensity in $\mathrm{T} 2 \mathrm{WI}$ in animals exposed to $15 \mathrm{~min}$ of hypoxia $(B)$, whereas persistent changes became visible in the ipsilateral cortex of animals recovering from prolonged hypoxia $(C)$. Note the high signal intensity of immobile protons of the s.c. fat layer in DWI.

probably reflects a weighted sum of the two compartments as the experimental diffusion sensitizing time $\left(\mathrm{T}_{\mathrm{M}}=100 \mathrm{~ms}\right)$ was long enough for water exchange to take place. Moreover, the intracellular $\mathrm{ADC}_{\mathrm{w}}$ is about an order of magnitude smaller than the extracellular $\mathrm{ADC}_{\mathrm{w}}(24,25)$. A narrowing of the extracellular space (26-28) due to the swelling of the cells may, therefore, cause at least part of the $\mathrm{ADC}_{\mathrm{w}}$ reduction. Because the cytotoxic edema can be visualized during the first $2-6 \mathrm{~h}$, it implies that the primary shift of water from extracellular to intracellular space is not yet entirely compensated by a subsequent transfer of water from blood to hypoxic-ischemic tissue after blood-brain barrier breakdown. In contrast, the accumulation of interstitial fluid as in vasogenic edema and subsequent tissue necrosis and gliosis may be visible by high signal intensity of T2WI. Such $\mathrm{T}_{2}$ prolongations reflect a dramatic increase of freely diffusible tissue water (Fig. 2C). They were only detected in the animals exposed to $30 \mathrm{~min}$ and $1 \mathrm{~h}$ of hypoxia (groups D and E). As the vasogenic edema can spread out along fiber tracks preferably along association fibers, the extent of the vasogenic edema is not confined to the extent of the primary cytotoxic edema.

Based on the observation that, after $15 \mathrm{~min}$ of hypoxia, cellular swelling was not followed by $\mathrm{T}_{2}$ prolongation of brain tissue nor by any increase in water content, we are left with the question of what metabolic effect underlies a short term hypoxia-ischemia. In making a hypothesis within this context, the following two findings are weighty. First, the normal pattern of T2WI contrast observed $2 \mathrm{~d}$ after recovery was entirely consistent with that seen in animals with CCA ligation alone and, notably, in animals of the control group. Second, the occurrence of isolated selective neuronal necrosis indicated that the hypoxic-ischemic brain tissue was still a functionally and structurally intact zone. Thus, it is reasonable to assume that the reestablishment of physiologic water compartmentation after short term hypoxia-ischemia occurs as a consequence of a recovered energy metabolism. Therefore, the dependence of 

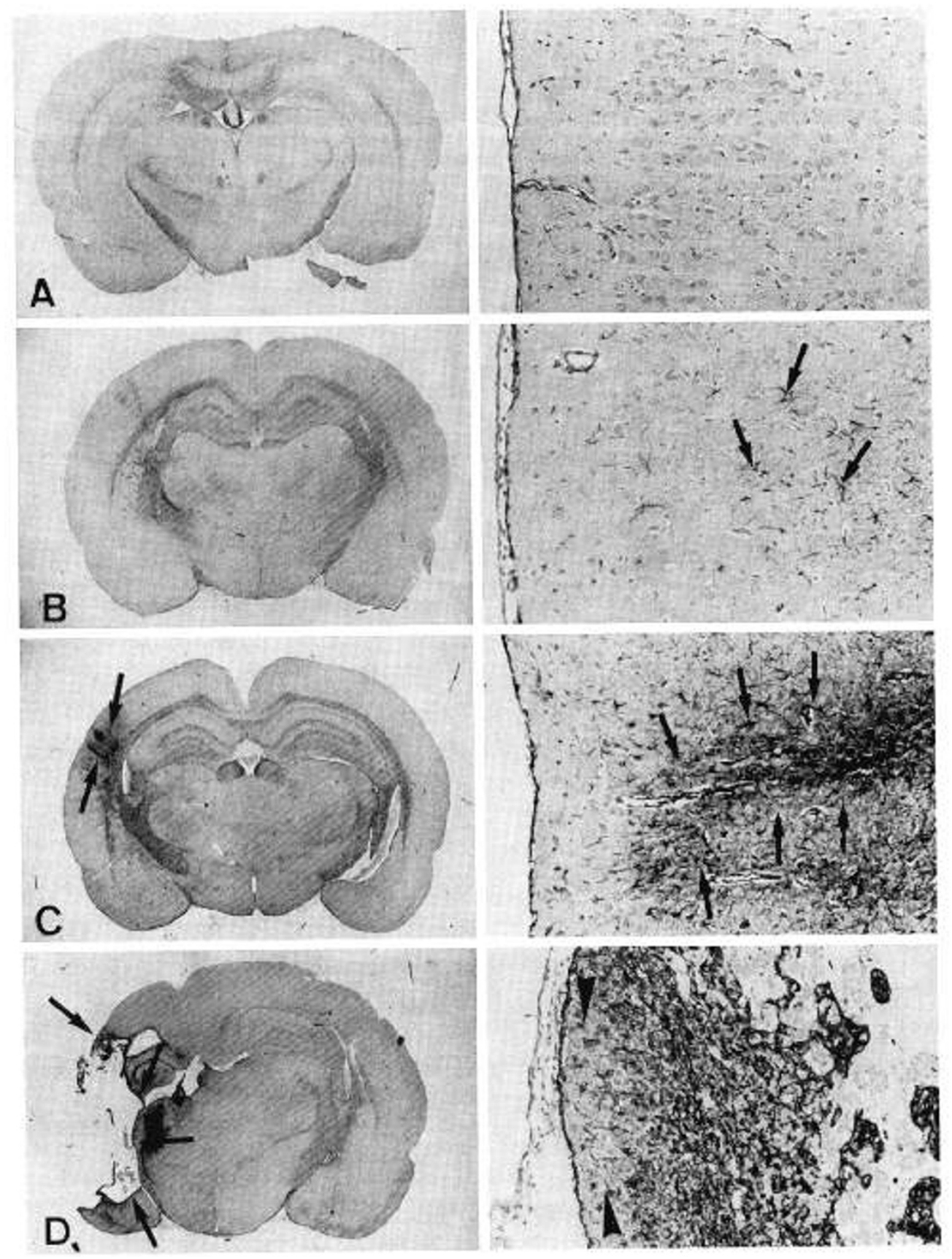

Figure 3. GFAP immunocytochemistry for reactive astrocytes. The brain sections were cut at the level of the dorsal hippocampus at $21 \mathrm{~d}$ (left column, overview; right column, higher magnification of parietal cortex). Section in $A$ demonstrates that CCA ligation without hypoxia produces no neuronal damage. Section in $B$ demonstrates only a few scattered GFAP-immunoreactive astrocytes (arrows) in the parietal cortex after 15 min of hypoxia-ischemia. In this case, no DWI hyperintensity was observed. When DWI hyperintensity was observed, numerous GFAP-immunoreactive astrocytes demarcated neuronal cortical damage in a columnar fashion (arrows in C). Section in $D$ demonstrates the outcome of hyopxia of $1 \mathrm{~h}$ duration. Almost one entire cortical hemisphere with the underlying subcortical structures has undergone necrosis and is replaced by a huge cystic infarction (arrows). Higher magnification (right column) shows that the subpial layer is preserved in a pseudolaminar fashion (arrowhead). Original magnifications: left column, $\times 20$; right column, $\times 180$.

brain water content on duration of hypoxia might, in turn, be biphasic rather than linear. Phase A of the hypothetical curve in Figure 4 represents a shift of water between the extracellular and intracellular compartment, i.e. cytotoxic edema, with only an insignificant increase of total brain water, whereas phase B describes an essentially linear increase in the extent of brain edema. We call the curvilinear zone at around $15 \mathrm{~min}$ of hypoxia the hypoxic-ischemic threshold. Support for this explanation is also derived from investigations in other animal models, such as the rat stroke model of middle cerebral artery occlusion (28) and the four-vessel occlusion model (29). It has to be pointed out that, for the various animal models and whether immature or adult animals (4), reduction in cerebral blood flow may differ and, thus, brain edema evolution may occur time-shifted (30).

The following two observations in rats recovering from long term hypoxia-ischemia are in agreement with the hypothesis of a biphasic development of edema. First, the extent and inten- 


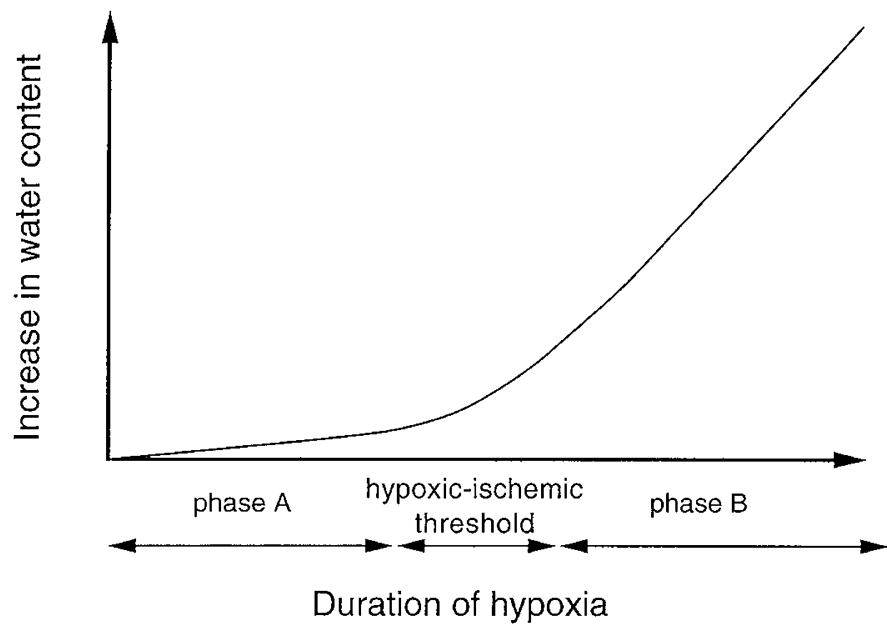

Figure 4. Schematic representation of the dependence of brain water content on duration of hypoxia-ischemia. The curvilinear zone is called the hypoxicischemic threshold.

sity of the hyperintense area in DWI are smaller compared with that of short term hypoxia-ischemia. Second, in a certain percentage of T2WI taken within the same time frame, some early hyperintensity from vasogenic brain edema are visible. Both effects may be due to a more severe blood-brain barrier breakdown caused by the longer duration of hypoxia-ischemia. The subsequent bulk water uptake into the extracellular compartment (phase B in Fig. 4) counteracts the abnormal uptake of water by injured brain cells in a more pronounced manner, and thus leads to a weakening of the underlying DWI effect.

It is apparent from this study that a primary disturbance of physiologic water compartmentation leading to a cytotoxic edema is reversible for short term hypoxia-ischemia, whereas long term hypoxia-ischemia generates bulk water shifts resulting in vasogenic edema and subsequent necrosis and gliosis. Therefore, we conclude that a tolerance interval for the duration of hypoxia must exist after which a disturbed brain metabolism and its cellular consequences, e.g. cell membrane integrity, are largely reversible. It follows that DWI hyperintensity per se does not implicate a permanent brain lesion.

Acknowledgments. The authors thank Dr. M. HoehnBerlage of the Max-Planck-Institute for Neurologic Research in Cologne for his helpful comments. We are also obliged to Dr. P. Brunner for time on the Biospec 47/30 of Spectrospin AG, Fällanden, Switzerland.

\section{REFERENCES}

1. Rice JE, Vannucci RC, Brierley JB 1981 The influence of immaturity on hypoxicischemic brain damage in the rat. Ann Neurol 9:131-141

2. Vannucci RC, Christensen MA, Yager JY 1993 Nature, time-course, and extent of cerebral edema in perinatal hypoxic-ischemic brain damage. Pediatr Neurol 9:29-34
3. Towfighi J, Yager JY, Housman C, Vannucci RC 1991 Neuropathology of remote hypoxic-ischemic damage in the immature rat. Acta Neuropathol 81:578--587

4. Mujsce DJ, Christensen MA, Vannucci RC 1990 Cerebral blood flow and edema in perinatal hypoxic-ischemic brain damage. Pediatr Res 27:450-453

5. Klein HC, Krop-van-Gastel W, Go KG, Korf J 1993 Prediction of specific damage or infarction from the measurement of tissue impedance following repetitive brain ischemia in the rat. Neuropathol Appl Neurobiol 19:57-65

6. Williams GD, Palmer C, Roberts RL, Heitjan DF, Smith MD $1992{ }^{31} \mathrm{P}$ NMR spectroscopy of perinatal hypoxic-ischemic brain damage: A model to evaluate neuroprotective drugs in immature rats. NMR Biomed 5:145-53

7. Yager JY, Brucklacher RM, Vannucci RC 1992 Cerebral energy metabolism during hypoxia-ischemia and early recovery in immature rats. Am J Physiol 262:H672-H677

8. Yager J, Towfighi J, Vannucci RC 1993 Influence of mild hypothermia on hypoxicischemic brain damage in the immature rat. Pediatr Res 34:525-529

9. Levine S 1960 Anoxic-ischemic encephalopathy in rats. Am J Pathol 36:1-17

10. Campbell LR, Bunyapen C, Holmes GL, Howell CG, Kanto WP 1988 Right common carotid artery ligation in extracorporeal membrane oxygenation. J Pediatr 113:110113

11. Griffin MP, Minifee PK, Landry SH, Allison PL, Swischuk LE 1992 Neurodevelopmental outcome in neonates after extracorporeal membrane oxygenation: cranial magnetic resonance imaging and ultrasonography correlation. J Pediatr Surg 27:33-35

12. Taylor GA, Short BL, Fitz CR 1989 Imaging of cerebrovascular injury in infants treated with extracorporeal membrane oxygenation. J Pediatr 114:635-639

13. Moseley ME, Cohen Y, Mintorovich J, Chileuitt L, Shimizu H, Kucharczyk J, Wendland MF, Weinstein PR 1990 Early detection of regional cerebral ilschemia in cats: comparison of diffusion- and $\mathrm{T}_{2}$-weighted MRI and spectroscopy. Magn Reson Med 14:330-346

14. Verheul HB, Berkelbach van der Sprenkel JW, Tulleken CAF, Tamminga KS, Nicolay K 1992 Temporal evolution of focal cerebral ischemia in the rat assessed by $\mathrm{T}_{2}$-weighted and diffusion-weighted magnetic resonance imaging. Brain Topogr 5:171-176

15. Stejskal EO, Tanner JE 1965 Spin diffusion measurements: spin echoes in the presence of a time-dependent field gradient. J Chem Phys 42:288-292

16. Klatzo I 1994 Evolution of brain edema concepts. Acta Neurochir Suppl 60:3-6

17. Milhorat TH 1992 Classification of the cerebral edemas with reference to hydrocephalus and pseudotumor cerebri. Child's Nerv Syst 8:301-306

18. Hennig J, Nauerth A, Friedburg H 1986 RARE-imaging: A fast imaging method for clinical MR. Magn Reson Med 3:823-833

19. Merboldt KD, Hänicke W, Frahm J 1985 Self-diffusion NMR imaging using stimulated echoes. J Magn Reson 64:479-486

20. Le Bihan D 1990 Magnetic resonance imaging of perfusion. Magn Reson Med 14:283-292

21. McLendon RE, Bigner DD 1994 Immunohistochemistry of the glial fibrillary acidic protein: Basic and applied considerations. Brain Pathol 4:221-228

22. Smith TW, Nikulasson S, DeGirolami U, DeGennaro LJ 1993 Immunohistochemistry of synapsin I and synaptophysin in human nervous system and neuroendocrine tumors. Applications in diagnostic neuro-oncology. Clin Neuropathol 12:335-342

23. Benveniste H, Hedlund LW, Johnson GA 1992 Mechanism of detection of acute cerebral ischemia in rats by diffusion-weighted magnetic resonance microscopy. Stroke 23:746-754

24. van Zijl PCM, Moonen CTW, Faustino P, Pekar J, Kaplan O, Cohen JS 1991 Complete separation of intracellular and extracellular information in NMR spectra of perfused cells by diffusion-weighted spectroscopy. Proc Natl Acad Sci USA $88: 3228-3232$

25. Williams CE, Gunn A, Gluckman PD 1991 Time course of intracellular edema and epileptiform activity following prenatal cerebral ischemia in sheep. Stroke 22:516521

26. Bondareff W, Myers RE, Brann AW 1970 Brain extracellular space in monkey fetuses subjected to prolonged partial asphyxia. Exp Neurol 28:167-178

27. Gyngell ML, Back T, Hoehn-Berlage M, Kohno K, Hossmann, K-A 1994 Transient cell depolarization after permanent middle cerebral artery occlusion: an observation by diffusion-weighted MRI and localized ${ }^{1}$ H-MRS. Magn Reson Med 31:337-341

28. Haraldseth O, Jones RA, Müller TB, Jynge P, Rinck PA, Oksendahl AN 1993 Early hyperintensity in diffusion weighted MR imaging is reversible after regional ischaemia of short duration. Twelfth Annual Meeting of the Society of Magnetic Resonance in Medicine, New York, p 593(abstr)

29. Todd NV, Picozzi P, Crockard HA, Ross Russell RW 1986 Duration of ischemia influences the development and resolution of ischemic brain edema. Stroke 17:466471

30. Pierpaoli C, Righini A, Linfante I, Tao-Cheng JH, Alger JR, DiChiro G 1993 Histopathologic correlates of abnormal water diffusion in cerebral ischemia: diffusion-weighted MR imaging and light and electron microscopy study. Radiology 189:439-448 